\title{
Clinical and functional results of radiofrequency ablation and microwave ablation in patients with benign thyroid nodules
}

Mirkhalig Javadov, MD, Emrah Karatay, MD, Mustafa U. Ugurlu, MD.

\begin{abstract}
الأهداف : لتحديد جودة الاستئصال بالترددات الراديوية عن طريق الجلد

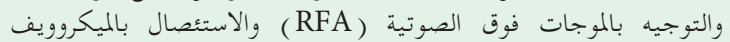

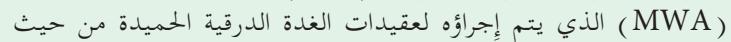
النتائج السريرية والوظيفيه.

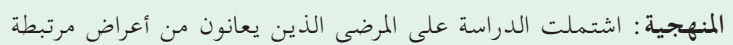

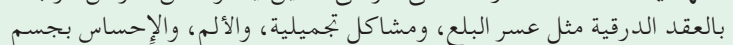

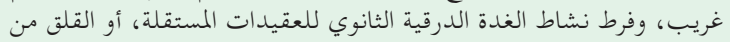

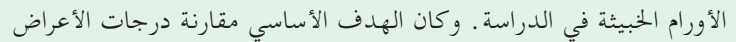

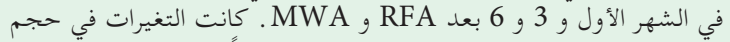
العقيدات والاختلاف في وظائف الغدة الدرقية أهدافًا ثانوية .

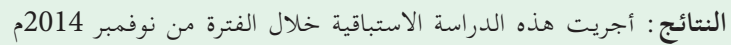

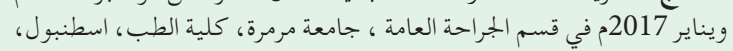

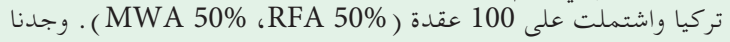

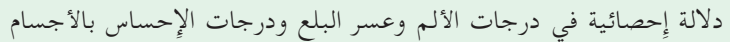

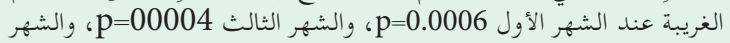

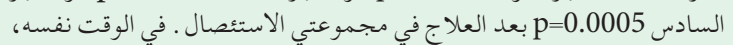

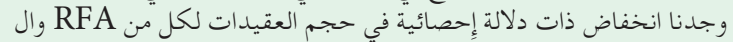

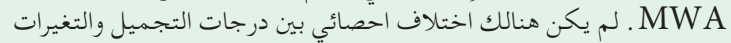

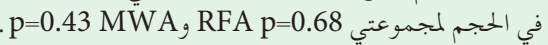

الحلاصة: أن الاستئصال بالترددات الراديوية عن طريق الجلد والماتل والتوجيه

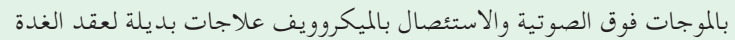

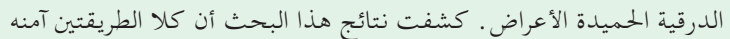
وفعاله.
\end{abstract}

Objectives: To determine how well ultrasoundguidance percutaneous radiofrequency ablation (RFA) and microwave ablation (MWA) performed for benign symptomatic thyroid nodules in terms of clinical and functional outcomes.

Methods: Patients who had a thyroid nodulelinked symptoms acting as dysphagia, cosmetic issues, pain, a foreign body sense, hyperthyroidism secondary to autonomous nodules, or concern of malignancy were involved in the study. The primary was the comparison in symptom scores obtained at 1,3 , and 6 months after RFA and MWA. The volume alterations in nodules and alterations in thyroid gland functions were secondary objectives.

Results: This prospective study carried out from November 2014 and January 2017 at the General Surgery Department, Marmara University, Faculty of Medicine, Istanbul, Turkey included a total of 100 nodules (50\% MWA, 50\% RFA). There were statistically significance in pain scores, dysphagia scores, and foreign body sensation scores at 1,3 , and 6 months after therapy in both ablation groups $(p=0.0006, p=00004, p=0.0005)$. At the same time, there were statistically significant reductions in size and volume of the nodules for RFA and MWA ( $p=0.0004$, $p=0.0003)$. There was no significant difference between the RFA and MWA groups' cosmetic scoring and volume changes $(p=0.68, p=0.43)$.

Conclusion: Alternative therapies for benign symptomatic thyroid nodules include RFA and MWA. The findings of this research revealed that both approaches are safe and effective.

Keywords: thyroid, benign nodule, radiofrequency ablation, microwave ablation, symptom score

Saudi Med J 2021; Vol. 42 (8): 838-846 doi: 10.15537/smj.2021.42.8.20210307

From the Department of General Surgery (Javadov), Faculty of Medicine, Yeditepe University; from the Department of Radiology (Karatay), Marmara University Pendik Training and Research Hospital; and from the Department of General Surgery (Ugurlu), Faculty of Medicine, Marmara University, Istanbul, Turkey.

Received 21st April 2021. Accepted 18th June 2021.

Address correspondence and reprint request to: Dr. Mirkhalig Javadov, Department of General Surgery, Yeditepe University Faculty of Medicine, Istanbul, Turkey.E-mail: dr.mjavadov@gmail.com ORCID ID: https://orcid.org/0000-0002-4288-0400 
T hyroid nodules are important clinical problems and in some cases require treatment. The palpable nodules are observed in $5-10 \%$ of the population in clinical practice, and new thyroid nodules can develop in almost $10 \%$ of patients during their lifetime. ${ }^{1,2}$ Clinically non-palpable nodules are more likely to be detected by ultrasound (US), and the rate of nodule detection with US imaging for screening purposes can reach up to $70 \% .^{3}$ The widespread use of US causes further detection of asymptomatic nodules. Similar data were reported in autopsy studies and the presence of a much higher rate of thyroid nodules was proven. ${ }^{3,4}$

Despite the fact that the majority of thyroid nodules diagnosed are benign and do not cause significant clinical symptoms, some nodules may lead to compression-related symptoms. In addition, thyrotoxic symptoms may develop due to hyperfunctioning of some nodules. ${ }^{3-5}$ The ideal method to decide the need for treatment is a cytological result obtained with fine-needle aspiration biopsy (FNAB). A new study issue is determining the optimal therapy technique for cases with cytologically verified benign thyroid nodules (BTN), especially as a minimally invasive approach is desired..$^{6,7}$

Thyroid nodules are frequently small sizes and benign, and needing no treatment. Some of these nodules enlarge with time, giving in local symptoms requiring treatment, especially due to compression. ${ }^{8,9}$ In a few previous studies on thyroid nodules, combinations of thermal ablative methods and radioiodine-treatment (RIT) were used, and positive results were obtained. However, new studies with high case numbers are needed in terms of optimal evaluation of efficacy. ${ }^{9-11}$ In the past, levothyroxine has also been used in the medication of multinodular goiter. ${ }^{12}$ Because levothyroxine medication involves negative effects such decreased bone density and atrial fibrillation; and RIT complications may develop in different organs secondary to radiation exposure, both methods were discontinued for the treatment of BTN. ${ }^{10-12}$

Due to the inadequacy of medical methods, studies on non-surgical minimally invasive alternative treatments have been initiated in different centers. The efficiency of minimally invasive approaches have been increasingly reported in clinical studies. ${ }^{13-15}$ Minimally

Disclosure. Authors have no conflict of interests, and the work was not supported or funded by any drug company. invasive procedures include ethanol ablation (EA), percutaneous laser ablation (PLA), microwave ablation (MWA), and radiofrequency ablation (RFA). ${ }^{13-17}$ High-intensity focused ultrasound (HIFU) looks to be a noninvasive therapeutic option for BTN. With this method, a volume decreasing of over $50 \%$ was obtained at the end of a 24-month follow-up. ${ }^{18}$

Local ablation of BTN is a current issue, and radiofrequency ablation is frequently used as an alternative to surgical treatments. Radiofrequency ablation has been recognized as a reliable alternative and both BTN and recurrent thyroid malignancies can be treated with this strategy. ${ }^{13,19}$ In one of the recent studies, a decrease in volume of 30-60\% at one month follow-up, and $50-85 \%$ at 6 months was detected in benign cold thyroid nodules treated with RFA, as well as a decrease in cosmetic complaints and compression symptoms. ${ }^{20}$ After the radiofrequency treatment was applied for autonomic thyroid nodules, it was determined that the high thyroid hormone levels before treatment returned to normal, and also there was a reduction in the size of the nodules. ${ }^{19,20}$ Although complications of RFA application such as pain, voice change, hematoma, skin burn, thyrotoxicosis, hypothyroidism, fever can occur, the majority of patients recovered over time without a permanent sequela. ${ }^{21,22}$

Microwave ablation, which is among the thermal ablative methods, is increasingly used as an another option to surgery in the treatment of thyroid nodules. ${ }^{14,15}$ The liver, kidneys, adrenal glands, spleen, and lungs are all treated with this technique, which involves triggering tissue necrosis using heat. ${ }^{22-25}$ When compared to RFA, it has been determined that MWA treatment has advantages such as providing a larger ablation volume, more homogeneous distribution of heat, and less heat loss. The most important advantage of MWA application is that it is less painful. ${ }^{21-25}$

In this study, the clinical and functional results were examined using RFA and MWA treatment methods cytology-confirmed benign thyroid nodules. The current study's primary aim was to assess the changes of symptoms such as pain, dysphagia, and foreign body sensation 1, 3, and 6 months after RFA and MWA procedures. A secondary objective was to see how RFA and MWA treatments affected thyroid nodule volume, function tests, and complication rates.

Methods. The local ethics committee reviewed and approved this prospective randomized study. The patients were selected among those with thyroid nodule complaints who were referred to the General Surgery 
Department, Marmara University, Faculty of Medicine, Istanbul, Turkey between November 2014 and January 2017. Routine hemogram and coagulation tests were completed for all patients. In addition, nodule volume measurements via US, thyroid function tests, and FNAB was performed to determine if the nodule was benign or malignant. Because it included human objects, the Helsinki Declaration was adhered throughout the study. After giving verbal and written informed consent on the procedure to the patients, the potential side effects and complications (hematoma, infection, burns, hoarseness, hypothyroidism, and so on) related to the procedure were explained to the patients and a signed consent was obtained from each participant.

Patients with compression symptoms or cosmetic problems, diagnosed as BTN with FNAB performed at least twice, nodule diameter $\geq 1 \mathrm{~cm}$, solid thyroid nodules, and older than 18 years were included in the study. Patients younger than 18 years old, diagnosed with malignancy as a result of biopsy, or who did not accept the risk of the procedure were excluded from the study and referred to other units to receive appropriate treatment.

Pain, dysphagia, foreign body sensation, and cosmetic problems were evaluated while examining the symptoms related to thyroid nodules. Of the 100 cases with symptomatic BTN included in the study, 50 of them received RFA and 50 received MWA. Patients taking anticoagulants stopped treatment 7-10 days before the procedure, and coagulation levels were checked before ablation to ensure they were within normal levels.

A $10-\mathrm{cm}$ visual analog scale was used to assess the patients' other subjective symptoms, including as pain, dysphagia, foreign body sensation, and hoarseness $(1-10 \mathrm{~cm})$. Cosmetic scoring is based on the rating system of the World Health Organization (WHO). 1- no palpable nodule, 2- a palpable nodule with no cosmetic problem, 3- the presence of nodules visible by swallowing, and 4- the presence of prominent nodules, according to this scoring system (Figure 1). ${ }^{20,26}$

Ultrasound examination. Prior to ablation treatments, US was used to analyze the size, shape, echogenicity, calcification status, solid/cystic ratio, and internal vascularity of the nodules. B-mode US volume measurements and interventional radiology procedures were performed by an experienced radiologist. The volumetric measurements were performed on US images obtained using a 7-18-Mhz linear array probe (Aplio 500, Tochigi, Japan) in the axial and sagittal planes. Two separate biopsies were taken from BTN for control

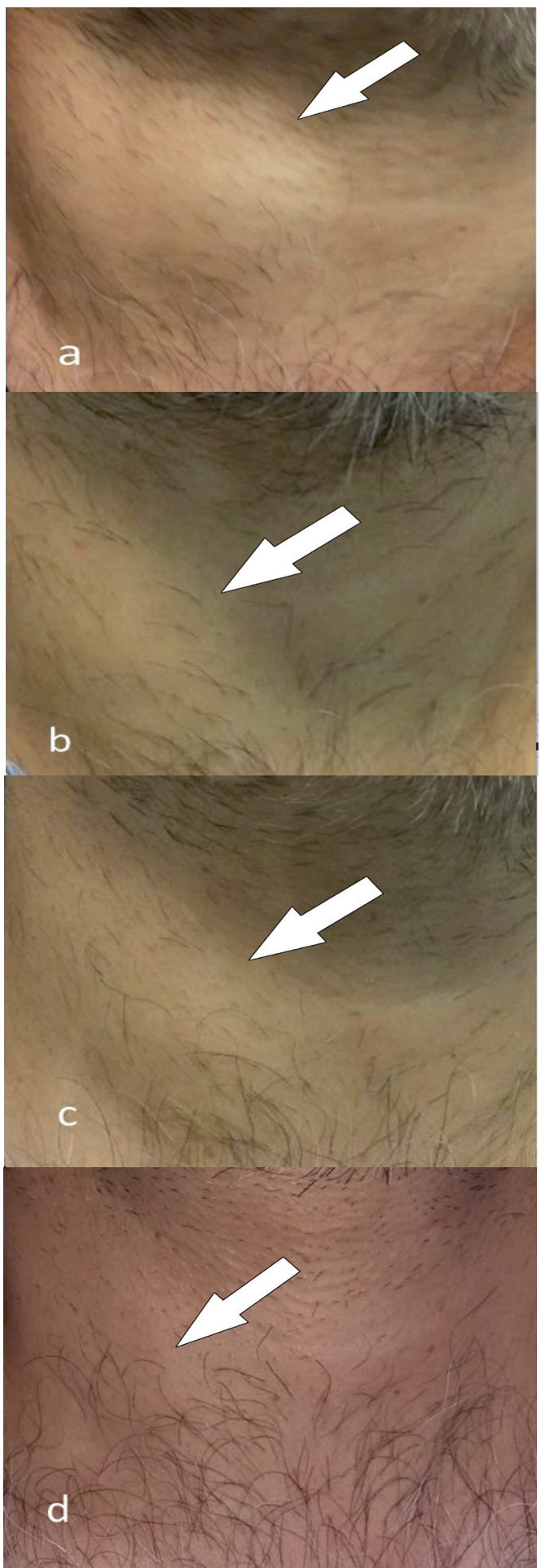

Figure 1 - Using the World Health Organization cosmetic scoring, a 50 year-old male patient who underwent radiofrequency ablation; A) before ablation (score 4), B) one month follow-up (score 3), C) 3 months follow-up (score 3), and D) 6 months follow-up (score 2) macroscopic view is available. 
purposes and cytological sampling was performed. The biopsies taken were reported cytopathological using the Bethesda classification (2). Volumetric measurements of the nodules were made with US examination. The volume was calculated using the formula $\mathrm{V}=$ $\mathrm{abc} / 6(\mathrm{a}=$ biggest diameter, $\mathrm{b}$ and $\mathrm{c}=$ other vertical diameters in millimeters). Physical examination, US evaluation, and thyroid function tests were performed on all patients who underwent ablation at 1,3 , and 6 months follow-up. Volume variability, echogenicity, intranodular vascularity, and remaining living parts of the nodules in US controls were re-evaluated, as the volume reduction ratio (VRR) of the nodules was calculated in percentages. Volume reduction ratio $(\%)=$ (index volume $(\mathrm{mL})$ - final volume $(\mathrm{mL}) \mathrm{x} 100)$ / index volume $(\mathrm{mL})$ was used in the calculations.

Radiofrequency ablation. Radiofrequency ablation procedures for all patients were performed as outpatient. During the process, an internal cooling bipolar system electrode (18 g thickness, length $70 \mathrm{~mm}$, active combustion type $7 \mathrm{~mm}$ ) and RF generator (Starmed, Viva RF system, South Korea) were used. By applying local anesthesia in accordance with the localization of the nodule, a skin incision of $2 \mathrm{~mm}$ in size was made, the electrode was placed in the deepest part of the nodule, and ablation was initiated using the "moving shot technique" (MST) method. The procedure was terminated after an average of 5-10 minutes of ablation to each nodule and all regions were hyperechoic. The patients were kept under observation for approximately 2 hours after the procedure for observation, oral analgesics were prescribed and the patients were discharged to be called for follow-up.

Microwave ablation. The microwave ablation method has been carried out with similar principles. The system consists of a generator operating with a microwave frequency and generating power (MedWaves, Microwave probes, San Diego, US), at a wavelength of $2.45 \mathrm{Ghz}$, and probes working accordingly. Ceramictipped probes are used for easy access to tissues. After local anesthesia, a $2 \mathrm{~mm}$ skin incision was made according to the localization of the nodule and the MWA probe was inserted into the nodule with the help of US. Transisthmic intervention was preferred to see the full length of the microwave probe and to preserve neurovascular structures, if possible. The appearance of microbubbles and hyperechogenic areas on US images during MWA showed the build-up of heat in the ablation area. Ablation was continued by advancing the MWA probe towards the other parts of the nodule, and then US was repeated to visualize local complications such as hemorrhage and hematoma.
Statistical analysis. The 21st version of SPSS software was used to conduct statistical analyses (IBM Corp., Armonk, N.Y., USA). Categorical variables (gender, medication status, thyroid function status, cosmetic scoring) were presented as frequency tables. Continuous variables (age, pain, dysphagia, foreign body sensation, nodule volume) were presented as mean \pm SD distribution. To see if the variables were normally distributed, the Kolmogorov-Smirnov test was utilized. Categorical variables in the RFA and MWA groups were compared using Chi-square and Fisher Exact tests. The variables that did not show a normal distribution or changes in pain, swallowing difficulties, and foreign body sensation were analyzed with the Mann-Whitney $\mathrm{U}$ test. In this research, a $p$-value $<0.05$ was considered statistically significant.

Results. A total of 100 patients, 27 (27\%) males and $73(73 \%)$ females were included in the study. Ablation procedure for a single benign thyroid nodule was performed for all patients. Radiofrequency ablation was applied to $50(50 \%)$ patients and MWA was applied to 50 (50\%). Between patients; the youngest age was 21 years old and oldest age was 77 , and both were female. The average age was $51.25 \pm 9.38$ for males, $46.90 \pm 11.50$ for females, and $48.08 \pm 11.09$ for all patients The RFA group consisted of $22 \%$ males and $78 \%$ female patients. The MWA group consisted of 32\% males and 68\% females. The minimum age was 21 , the maximum was 77 , and the mean age was $48.28 \pm 11.36$ in the RFA group, and the minimum age was 28 , maximum 73 , and the mean age $47.88 \pm 10.93$ in the MWA group.

Firstly, thyroid functions were evaluated for each patient before ablation procedures. Of these, 83\% evaluated as euthyroid, $15 \%$ as hyperthyroid, and $2 \%$ as hypothyroid. When the thyroid function was re-checked 6 months after ablation, 93\% were evaluated as euthyroid, $6 \%$ as hyperthyroid, and $1 \%$ as hypothyroid. While $64 \%$ of the patients did not use any thyroid medication before the procedure, 36\% were using thyroid medications. As a result of thyroid function tests being performed 6 months after ablation, $31 \%$ discontinued their thyroid medication, and 5\% continued their medication (Table 1). While 68\% did not use any medication before RFA, 32\% were using thyroid medication. As a result of thyroid function tests being performed 6 months after ablation, thyroid medication was discontinued in all 16 patients who used medication. While $60 \%$ of the patients did not use any medication before MWA, 40\% were using thyroid medication. At 6 months follow-up after 
ablation, thyroid medication for $30 \%$ of the patients was discontinued.

Cosmetic scoring was determined from 1 to 4 . When all cases were evaluated, before ablation, the score was 2 in $25 \%$ of the patients, 3 in $37 \%$, and 4 in $38 \%$ of the patients. In the last follow-up at 6 months, the score was 1 in $46 \%$ of the patients, 2 in $41 \%$, and 3 in $13 \%$ of the patients. Similarly, cosmetic scoring was available at 1 and 3 months after ablation (Table 2). No statistically significant difference was found when cosmetic scoring was compared at 6 months follow-up after RFA and MWA ( $p=0.68)$.

Before ablation procedures, the average pain score was $4.48 \pm 1.73$, the dysphagia score was $4.10 \pm 2.16$, and the foreign body score was $5.16 \pm 2.29$. At 6 months follow-up, the average pain score was $1.18 \pm 0.39$,

Table 1 - Thyroid medication before and after ablation, thyroid function change.

\begin{tabular}{lccccc}
\hline $\begin{array}{l}\text { Ablation } \\
\text { technique }\end{array}$ & $\begin{array}{c}\text { Thyroid } \\
\text { function }\end{array}$ & \multicolumn{2}{c}{$\begin{array}{c}\text { Pre-treatment } \\
\mathrm{n}\end{array}$} & $\begin{array}{c}\text { 6 months } \\
\text { post-ablation } \\
\mathrm{n}\end{array}$ & $(\%)$ \\
\hline $\begin{array}{l}\text { Radiofrequency } \\
\text { ablation }\end{array}$ & & & & & \\
$\quad \begin{array}{l}\text { Thyroid } \\
\text { medication }\end{array}$ & $(+)$ & 16 & $(32)$ & 0 & $(0)$ \\
Thyroid & $(-)$ & 34 & $(68)$ & 50 & $(100)$ \\
function & euthyroid & 39 & $(78)$ & 50 & $(100)$ \\
& hyperthyroid & 10 & $(20)$ & 0 & $(0)$ \\
Microwave & hypothyroid & 1 & $(2)$ & 0 & $(0)$ \\
ablation & & & & & \\
Thyroid & $(+)$ & 20 & $(40)$ & 5 & $(10)$ \\
medication & $(-)$ & 30 & $(60)$ & 45 & $(90)$ \\
Thyroid & euthyroid & 44 & $(88)$ & 43 & $(86)$ \\
function & hyperthyroid & 5 & $(10)$ & 6 & $(12)$ \\
& hypothyroid & 1 & $(2)$ & 1 & $(2)$ \\
\hline
\end{tabular}

Table 2 - Cosmetic score change before and after ablation.

\begin{tabular}{ccccccccc}
\hline $\begin{array}{l}\text { Cosmetic } \\
\text { scoring }\end{array}$ & Pre-ablation & $\begin{array}{c}1 \text { month } \\
\text { post-ablation }\end{array}$ & $\begin{array}{c}3 \text { months } \\
\text { post-ablation }\end{array}$ & $\begin{array}{c}6 \text { months } \\
\text { post-ablation }\end{array}$ \\
\hline$R F A$ & & & & & & & & \\
1 & 0 & $(0)$ & 1 & $(2)$ & 10 & $(20)$ & 23 & $(46)$ \\
2 & 12 & $(24)$ & 25 & $(50)$ & 28 & $(56)$ & 19 & $(38)$ \\
3 & 19 & $(38)$ & 19 & $(38)$ & 11 & $(20)$ & 8 & $(16)$ \\
4 & 19 & $(38)$ & 5 & $(10)$ & 1 & $(2)$ & 0 & $(0)$ \\
$M W A$ & & & & & & & & \\
1 & 0 & $(0)$ & 1 & $(2)$ & 9 & $(18)$ & 23 & $(46)$ \\
2 & 13 & $(26)$ & 19 & $(38)$ & 23 & $(46)$ & 22 & $(44)$ \\
3 & 18 & $(36)$ & 23 & $(46)$ & 17 & $(34)$ & 5 & $(10)$ \\
4 & 19 & $(38)$ & 7 & $(14)$ & 1 & $(2)$ & 0 & $(0)$ \\
\hline \multicolumn{8}{c}{ Values are presented as numbers and percentages (\%). } \\
\hline
\end{tabular}

dysphagia score was $1.16 \pm 0.37$, and foreign body score was $1.48 \pm 0.6$ (Table 3 ). There was a statistically significant difference between all 3 scores at the pre-ablation and at 6 months follow-up ( $p=0.0006, p=00004, p=0.0005$ ). When the RFA and MWA study groups were compared, there was no statistically significant difference between all scores changes $(p=0.59)$.

The mean volume reduction rates in the RFA study group at the end of 1,3 , and 6 months were $42 \%$, $56 \%$, and $65 \%$, respectively. In the MWA study group, the mean volume reduction rates at the end of 1,3 , and 6 months were $46 \%, 64 \%$, and $68 \%$, respectively (Figure 2). When the nodule volumes pre-treatment and at 6 months after procedure were compared between the RFA and MWA study groups, no statistically significant difference was found ( $p=0.43$ ) (Table 4 ). In the RFA and MWA study groups, a statistically significant decrease was observed in the mean solid nodule volume between pre-treatment and at 6 months after procedure (for RFA $[p=0.0004]$ and MWA $[p=0.0003])$.

Discussion. Until recently, surgery has been the main treatment option in the treatment of BTN. However, surgery may have undesirable effects such as nerve paralysis, long hospital stay, difficulty in reoperation, scarring, and permanent hypothyroidism/ hypoparathyroidism. ${ }^{2-5}$ Medical suppression treatments of thyroid nodules are often unsuccessful and do not contribute to the disappearance of complaints such as a feeling of pressure on the neck and cosmetic problems. Moreover, undesirable effects such as atrial fibrillation and decreased bone density may occur. ${ }^{10-12}$ For these reasons, nonsurgical minimally invasive alternative therapies have been investigated by an increasing amount of clinical studies.

Alternative and minimally invasive methods include RFA, MWA, EA, and PLA. ${ }^{14-20}$ Ethanol ablation is frequently used in the minimally invasive treatment of cystic thyroid nodules as an alternative to surgery. ${ }^{16,17,26}$ Radiofrequency ablation has also been shown to be a successful alternative to surgical therapy as it provides local ablation of BTN via thermal energy. In benign cold nodules treated with RFA, a decrease in volume was found $32.7-58.2 \%$ at the first one month follow-up, $50.7-84.8 \%$ at 6 months follow-up, and a decrease was observed in cosmetic complaints and compression symptoms. ${ }^{27}$ In another study involving 66 cold thyroid nodules undergoing RFA, 54\% volume reduction rates at one month and $78.6 \%$ at 12 months were found. In the same study, in $53 \%$ of the patient group with 28 toxic nodules, antithyroid medical treatment was discontinued at 12 months follow-up 
RFA and MWA in thyroid nodules ... Javadov et al

Table 3 - Before and after ablation pain score, dysphagia score, foreign body sensation changes.

\begin{tabular}{lccccc}
\hline Procedure type & Pre-ablation & $\begin{array}{c}1 \text { month } \\
\text { post-ablation }\end{array}$ & $\begin{array}{c}3 \text { months } \\
\text { post-ablation }\end{array}$ & $\begin{array}{c}6 \text { months } \\
\text { post-ablation }\end{array}$ & $P$-value \\
\hline$R F A$ & & & & & \\
Pain score & $4.37 \pm 1.74$ & $2.54 \pm 1.03$ & $1.60 \pm 0.63$ & $1.18 \pm 0.38$ & $<0.001$ \\
Dysphagia score & $4.10 \pm 2.15$ & $2.44 \pm 1.10$ & $1.48 \pm 0.64$ & $1.16 \pm 0.37$ & $<0.001$ \\
Foreign body & $5.16 \pm 2.29$ & $3.20 \pm 1.44$ & $2.02 \pm 0.95$ & $1.48 \pm 0.61$ & $<0.001$ \\
$M W A$ & & & & \\
Pain score & $4.56 \pm 2.26$ & $2.80 \pm 1.17$ & $1.88 \pm 0.62$ & $1.22 \pm 0.41$ & $<0.001$ \\
Dysphagia score & $4.62 \pm 2.14$ & $2.80 \pm 1.32$ & $1.72 \pm 0.75$ & $1.14 \pm 0.35$ & $<0.001$ \\
Foreign body & $5.70 \pm 2.04$ & $3.40 \pm 1.51$ & $2.16 \pm 1.05$ & $1.50 \pm 0.61$ & $<0.001$ \\
\hline \multicolumn{5}{c}{ RFA: radiofrequency ablation, MWA: microwave ablation } \\
\hline
\end{tabular}

Table 4 - Change in nodule volumes and reduction rate (\%).

\begin{tabular}{|c|c|c|c|c|c|}
\hline $\begin{array}{l}\text { Ablation } \\
\text { type }\end{array}$ & Pre-ablation $(\mathrm{ml})$ & $\begin{array}{c}1 \text { month } \\
\text { post-ablation }(\mathrm{ml})\end{array}$ & $\begin{array}{c}3 \text { months } \\
\text { post-ablation }(\mathrm{ml})\end{array}$ & $\begin{array}{c}6 \text { months } \\
\text { post-ablation }(\mathrm{ml})\end{array}$ & $P$-value \\
\hline \multirow{3}{*}{ RFA } & $19.33 \pm 21$ & $10.39 \pm 12.18$ & $7.94 \pm 10.31$ & $5.77 \pm 6.93$ & \multirow{6}{*}{$>0.05$} \\
\hline & $(0.25-83.70)$ & $(0.15-56.33)$ & $(0.10-60.29)$ & $(0.10-36.80)$ & \\
\hline & $\%$ & $42 \%$ & $56 \%$ & $65 \%$ & \\
\hline \multirow{3}{*}{ MWA } & $19.50 \pm 27.36$ & $9.64 \pm 17.09$ & $5.93 \pm 8.06$ & $4.35 \pm 4.18$ & \\
\hline & $(0.49-185.73)$ & $(0.27-112.06)$ & $(0.02-44.56)$ & $(0.07-16.58)$ & \\
\hline & $\%$ & $46 \%$ & $64 \%$ & $68 \%$ & \\
\hline
\end{tabular}
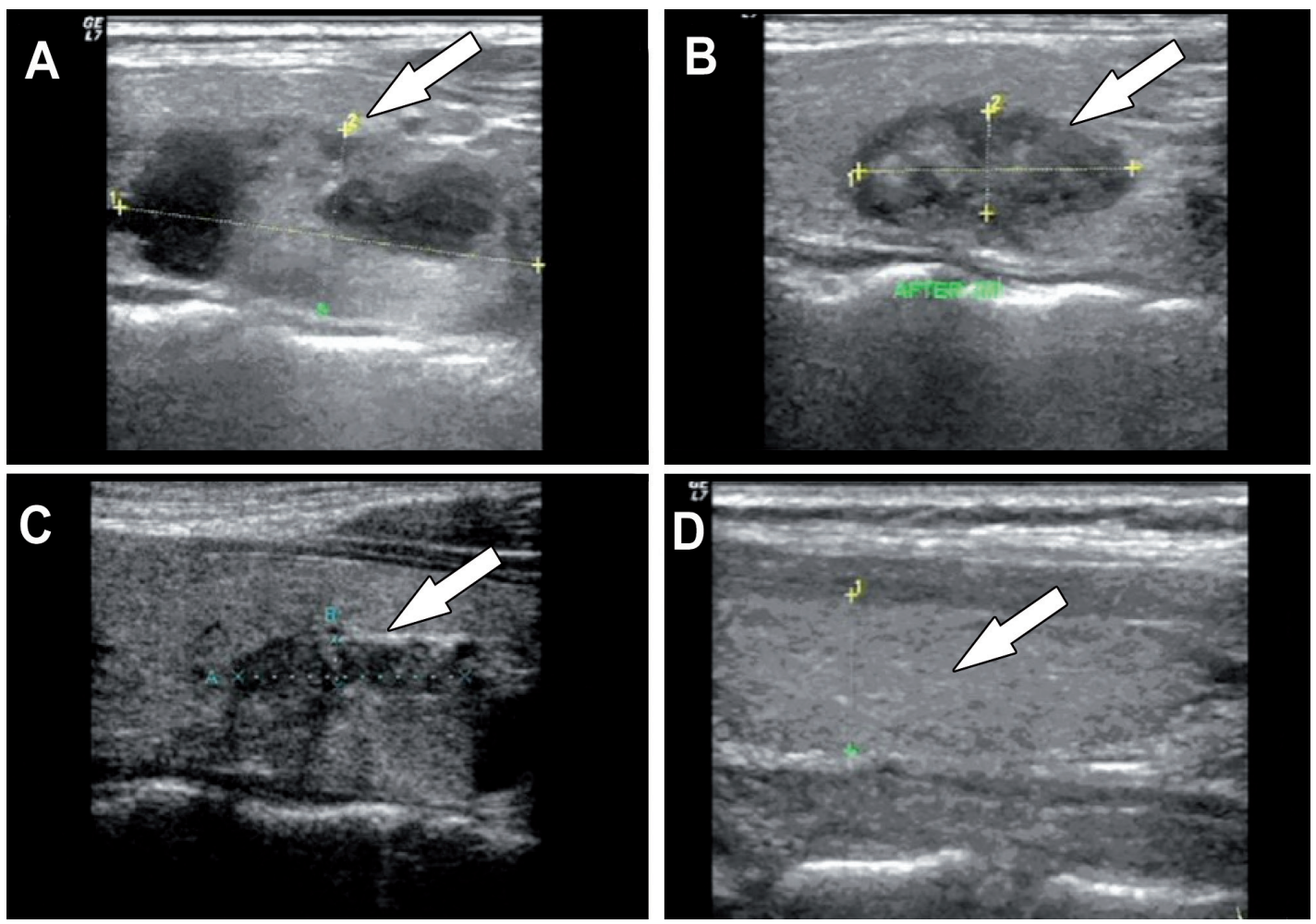

Figure 1 - Ultrasound follow-up of a 43 year-old female case that applied microwave ablation; A) before the procedure, B) one month, C) 3 months, and D) 6 months ultrasound examinations draw attention to the decrease in nodule sizes and volume. 
after the procedure. ${ }^{28}$ After RFA was performed for autonomic thyroid nodules, it was found that high thyroid hormone levels before the treatment returned to normal and there was also a reduction in the sizes of the nodule. ${ }^{19,20}$ Pain, voice alteration, hematoma, skin burn, thyrotoxicosis, hypothyroidism, and fever were all reported as side effects of radiofrequency treatment, although most patients healed without any long-term consequences. ${ }^{27}$

Microwave ablation is a newer thermal ablative method used in the treatment of thyroid nodules. When compared with RFA, it has been determined that MWA treatment has advantages such as providing larger ablation volume, more homogeneous distribution of heat, and less heat loss. ${ }^{14,15}$ Similar complications were seen with RFA after MWA, and almost all of them recovered without any permanent sequelae in followup. ${ }^{14,21}$ Wu et $\mathrm{al}^{14}$ performed US-guided one-session MWA on 121 BTN in 100 euthyroid patients. An internal cooled system was used, and nodule volumes were compared before and after treatment. The VRR was $57.66 \pm 22.95 \%$ at 3 months, $70.23 \pm 20.07 \%$, at 6 months, and $85.97 \pm 14.04 \%$ at 12 -month after ablation. Transient hoarseness developed in 2 patients and Horner's syndrome in 1 patient, which completely resolved at the end of the 2 nd month. ${ }^{14}$ Shi et al ${ }^{15}$ retrospectively compared the effectiveness of MWA and LA therapies for BTNs. Accordingly, it has been shown that this technique can be used effectively, because of the mean ablation time and complication rate are less in MWA. ${ }^{15}$

In the first study comparing MWA and RFA in BTN, the data of 260 patients were evaluated retrospectively. One hundred and two patients had a history of RFA and 158 patients had MWA, and the volume reduction rate at 6 months was $79.4 \%$ in the RFA group and $77.2 \%$ in the MWA Group. Throughout the procedures, a combination of $2 \%$ lidocaine and $0.9 \%$ normal saline was pumped into the thyroid capsule (using the hydrodissection technique) to protect the vascular systems and nerves close to the nodule. The MST was used during both ablations to keep the treatment safe and successful. ${ }^{29}$ In another retrospective study, the effectiveness of RFA, MWA, and high-intensity focused ultrasound (HIFU) techniques in BTN treatment were compared. At 3 months follow-up after treatment, 50\% volume reduction in RFA, 44\% in MWA, and 48\% in HIFU were achieved. Although RFA showed a slightly better mean volume reduction, there was no statistically significant difference when all 3 ablation methods were compared. ${ }^{30}$ In a retrospective study by Vorländer et $\mathrm{al}^{31} 25$ BTN were treated with MWA and 40 nodules with RFA. By using the "multiple overlapping shot technique", more than $50 \%$ volume reduction was earned after 3 months with both methods without moving the electrode/antenna. It was also stated that MWA required less shots to treat. Transient Horner's syndrome developed in one case after MWA in the same study. ${ }^{31}$ In a study by $\mathrm{Hu}$ et $\mathrm{al},{ }^{32} 3$-year data were retrospectively reviewed. Accordingly, it was found that both methods had a similar effect in reducing the volume of thyroid nodules in the first 3 months after treatment, and RFA was more successful in reducing the nodule volume compared to MWA at 6 and 12 months. Voice change developed in 2 cases after RFA and in 4 cases after MWA and was treated with medication. Hemorrhage developed in one case during a RFA procedure. ${ }^{32}$ The only prospective study comparing RFA and MWA was multicenter and non-randomized, and both methods were used for BTNs in 1,252 patients. It was stated that RFA was more successful in reducing nodule sizes and volume in the first 6 months and afterwards, and both methods could be used safely. Major complications developed after the procedures in 71 cases, including voice changes in 64 cases, nodule rupture in 6 cases, and Horner's syndrome in one case. ${ }^{33}$

The present study attracts attention as the first singlecenter prospective randomized study comparing RF and MWA in BTN. Almost all of the other studies reported in the literature were retrospective, and only one study was prospective. ${ }^{29-32}$ However, that prospective study was also multicentered and non-randomized..$^{33}$ Unlike other studies, RFA and MWA were applied only to solid thyroid nodules in our study. ${ }^{29-33}$ None of the patients developed hematoma, loss of voice, permanent nerve damage, skin infection, or abscess-like findings during and after the procedure. In one case who received only MWA, skin burn developed, and it resolved with medical treatment without permanent damage. Carbonization did not develop within the nodule in any of the patients who underwent MWA. ${ }^{29-31}$ Hydrodissection was not performed in any of the patients who underwent RFA or MWA. 30,32,33

Study limitations. First, there is a relatively low number of male cases. Second, there is a relatively low follow-up period 6 months after ablation procedures. Another limitation is that there is no prospective randomized study known in the literature in terms of comparing our data. Although a previous study was prospective, the ideal comparison could not be made because it was multicenter and non-randomized. ${ }^{33}$

In conclusion, RFA and MWA may be alternative intervention methods instead of surgery in the treatment of benign symptomatic thyroid nodules. The results 
in our study show that both RFA and MWA are safe and effective. Further studies with larger case numbers and longer follow-up periods, on the other hand, are required.

\section{References}

1. Trimboli P, Deandrea M. Treating thyroid nodules by radiofrequency: is the delivered energy correlated with the volume reduction rate? A pilot study. Endocrine. 2020; 69: 682-687.

2. Chung J, Lee YJ, Choi YJ, Ha EJ, Suh CH, CHoi M, et al. Clinical applications of Doppler ultrasonography for thyroid disease: consensus statement by the Korean Society of Thyroid Radiology. Ultrasonography 2020; 39: 315-330.

3. Russ G, Ben Hamou A, Poirée S, Ghander C, Menegauz F, Leenhardt $\mathrm{L}$, et al. Learning curve for radiofrequency ablation of benign thyroid nodules. Int J Hyperthermia 2021; 38: 55-64.

4. Erturk MS, Cekic B, Celik M. Microwave Ablation of Benign Thyroid Nodules: Effects on Systemic Inflammatory Response. J Coll Physicians Surg Pak 2020; 30: 694-700.

5. Deandrea M, Trimboli P, Garino F, Mormile A, Magliona G, Ramunni MJ, et al. Long-term efficacy of a single session of RFA for benign thyroid nodules: A longitudinal 5-year observational study. J Clin Endocrinol Metab 2019; 104: 3751-3756.

6. Cohen O, Lahav Y, Halperin D, Yehuda M. Surgeon-performed ultrasonographic evaluation and predication for large thyroid nodules-a case-control study. Surgery 2019; 166: 1148-1153.

7. Alexander LF, Patel NJ, Caserta MP, Robbin ML. Thyroid ultrasound: diffuse and nodular disease. Radiol Clin North Am 2020; 58: 1041-1057.

8. Wong R, Farrell SG, Grossmann M. Thyroid nodules: diagnosis and management. Med J Aust 2018; 209: 92-98.

9. Korkusuz H, Happel C, Koch DA, Gruenwald F. Combination of ultrasound-guided percutaneous microwave ablation and radioiodine therapy in benign thyroid disease: A 3-month follow-up study. Rofo 2016; 188: 60-68.

10. Mader A, Mader OM, Gröner D, korkusuz Y, Ahmad S, Gruwald F, et al. Minimally invasive local ablative therapies in combination with radioiodine therapy in benign thyroid disease: preparation, feasibility and efficiency - preliminary results. Int J Hyperthermia 2017; 33: 895-904.

11. Riley AS, McKenzie GAG, Green V, Schettino G, England RJA, Greenman J. The effect of radioiodine treatment on the diseased thyroid gland. Int J Radiat Biol 2019; 95:1718-1727.

12. Bin-Hong D, Fu-Man D, Yu L, Xu-Ping W, Bing-Feng B. Effects of levothyroxine therapy on bone mineral density and bone turnover markers in premenopausal women with thyroid cancer after thyroidectomy. Endokrynol Pol 2020; 71: 15-20.

13. Cappelli C, Franco F, Pirola I, Gandossi E, Marini F, Casella $\mathrm{C}$, et al. Radiofrequency ablation of functioning and nonfunctioning thyroid nodules: a single institution 12-month survey. J Endocrinol Invest 2020; 43: 477-482.

14. Wu W, Gong X, Zhou Q, Chen X, Chen X, Shi B. US-guided percutaneous microwave ablation for the treatment of benign thyroid nodules. Endocr J 2017; 64: 1079-1085.

15. Shi YF, Zhou P, Zhao YF, Liu WG, Tian SM, Liang YP. Microwave ablation compared with laser ablation for treating benign thyroid nodules in a propensity-score matching study. Front Endocrinol (Lausanne) 2019; 10: 874.
16. Deandrea M, Trimboli P, Creanza A, Garino F, Mormile A, Bertolino S, et al. Long-term follow-up of cystic thyroid nodules treated with percutaneous ethanol injection (PEI) using two different approaches. Eur J Endocrinol 2020; 183: 489-495.

17. Yang CC, Hsu Y, Liou JY. Efficacy of ethanol ablation for benign thyroid cysts and predominantly cystic nodules: a systematic review and meta-analysis. Endocrinol Metab (Seoul) 2021; 36: 81-95.

18. Trimboli P, Pelloni F, Bini F, Marinozzi F, Giovanella L. Highintensity focused ultrasound (HIFU) for benign thyroid nodules: 2-year follow-up results. Endocrine 2019; 65: 312-317.

19. Tang X, Cui D, Chi J, Wang Z, Wang T, Zhai B, et al. Evaluation of the safety and efficacy of radiofrequency ablation for treating benign thyroid nodules. J Cancer 2017; 8: 754-760.

20. Bisceglia A, Rossetto R, Garberoglio S, Franzin A, Cerato A, Maletta F, et al. Predictor analysis in radiofrequency ablation of benign thyroid nodules: A single center experience. Front Endocrinol (Lausanne) 2021; 12: 638880.

21. Cui T, Jin C, Jiao D, Teng D, Sui G. Safety and efficacy of microwave ablation for benign thyroid nodules and papillary thyroid microcarcinomas: A systematic review and metaanalysis. Eur J Radiol 2019; 118: 58-64.

22. Vo Chieu VD, Werncke T, Hensen B, Wacker F, Ringe KI. CT-guided microwave ablation of liver tumors in anatomically challenging locations. Cardiovasc Intervent Radiol 2018; 41: 1520-1529.

23. Luo N, Wang Y, Geng Z, Qin X. Analysis of feasibility, safety and effectiveness of ultrasound-guided percutaneous microwave ablation of splenic neoplasm. Oncol Lett 2018; 16: 4807-4812.

24. Zhou W, Herwald SE, Arellano RS. Computed tomographyguided microwave ablation of cystic renal cell carcinoma: assessment of technique and complications. J Vasc Interv Radiol 2021; 32: 544-547.

25. Chen B, Li W, Liu Y, Ren S, Wang L, Wang H, et al. The efficacy and complications of computed tomography guided microwave ablation in lung cancer. Ann Palliat Med 2020; 9: 2760-2765.

26. Park HS, Yim Y, Baek JH, Choi YJ, Shong YK, Lee JH. Ethanol ablation as a treatment strategy for benign cystic thyroid nodules: a comparison of the ethanol retention and aspiration techniques. Ultrasonography 2019; 38: 166-171.

27. Ha EJ, Baek JH, Lee JH. The efficacy and complications of radiofrequency ablation of thyroid nodules. Curr Opin Endocrinol Diabetes Obes 2011; 18: 310-314.

28. Spiezia S, Garberoglio R, Milone F, Remundo V, Caiazzo C, Assanti AP, et al. Thyroid nodules and related symptoms are stably controlled two years after radiofrequency thermal ablation. Thyroid 2009; 19: 219-225.

29. Yue WW, Wang SR, Lu F, Sun LP, Guo LH, Zhang YL, et al. Radiofrequency ablation vs. microwave ablation for patients with benign thyroid nodules: a propensity score matching study. Endocrine 2017; 55: 485-495.

30. Korkusuz Y, Gröner D, Raczynski N, Raczynski N, Relin O, Kingeter Y, et al. Thermal ablation of thyroid nodules: are radiofrequency ablation, microwave ablation and high intensity focused ultrasound equally safe and effective methods? Eur Radiol 2018; 28: 929-935.

31. Vorländer C, David Kohlhase K, Korkusuz Y, Erbelding C, Lunoldt W, Baser I, et al. Comparison between microwave ablation and bipolar radiofrequency ablation in benign thyroid nodules: differences in energy transmission, duration of application and applied shots. Int J Hyperthermia 2018; 35: 216-225. 
32. Hu K, Wu J, Dong Y, Yan Z, Lu Z, Liu L. Comparison between ultrasound-guided percutaneous radiofrequency and microwave ablation in benign thyroid nodules. J Cancer Res Ther 2019; 15: 1535-1540.
33. Cheng Z, Che Y, Yu S, Wang S, Teng D, Xu H. et al. US-guided percutaneous radiofrequency versus microwave ablation for benign thyroid nodules: a prospective multicenter study. Sci Rep 2017; 7: 9554. 